\title{
Analisis Faktor-Faktor yang Memengaruhi Kualitas Layanan di Bioskop XXI Lotte Bintaro Menggunakan Service Quality
}

\section{Analysis of Factors Affecting Service Quality in XXI Lotte Bintaro Cinema Using Service Quality}

\author{
Fahira Adya Prasetyo ${ }^{1 *}$, Widya Fitriani ${ }^{1}$, Muhammad Fadli Rifki ${ }^{1}$ \\ Program Studi Manajemen, Universitas Pembangunan Jaya, Jl. Cendrawasih Raya Blok B7/P, Ciputat, Kota \\ Tangerang Selatan 15413, Indonesia
}

Diterima: 16 Desember, 2019 / Disetujui: 20 Januari, 2020

\begin{abstract}
This study aims to determine which service quality must be maintained or which quality should be improved by a product or service company. In this study, we use several service theories, service quality, service quality from a variety of expert opinions and the method we use in this study is the Service Quality (Servqual) method which has five dimensions, namely reliability, responsiveness, assurance (assurance), empathy (empathy), and physical evidence (tangibles). The number of respondents in this study is Jabodetabek residents who have visited and used products and services from Cinema XXI under the auspices of PT Nusantara Sejahtera Raya and located at Lotte Bintaro Mall. After distributing questionnaires and getting questionnaire data with 38 respondents, the next step is processing data by the Servqual method. This method begins by calculating the gap/difference between customer expectations regarding services with the reality of service perceived by customers. This was done by distributing questionnaires through social media. The company does not only focus on film services but also on food and beverage products. The results showed that all dimensions of servqual have negative values, so to improve customer satisfaction, it is recommended that company management can improve service quality in five dimensions of servqual. The attribute that has the biggest negative value is "product quality according to price".
\end{abstract}

Keywords: Servqual, Service quality, Service, Product

\begin{abstract}
ABSTRAK
Penelitian ini bertujuan untuk mengetahui kualitas pelayanan mana yang harus dipertahankan atau kualitas mana yang harus ditingkatkan oleh suatu perusahaan produk maupun jasa. Dalam penelitian ini kami menggunakan beberapa teori jasa, kualitas jasa, kualitas pelayanan dari berbagai macam pendapat para ahli serta metode yang kami gunakan dalam penelitian ini adalah metode Service Quality (Servqual) yang memiliki lima dimensi yaitu keandalan (reliability), daya tanggap (responsiveness), jaminan (assurance), empati (empathy), dan bukti fisik (tangibles). Jumlah responden dalam penelitian ini adalah warga Jabodetabek yang telah mengunjungi dan menggunakan produk dan jasa dari Cinema XXI yang berada di bawah naungan PT Nusantara Sejahtera Raya dan terletak di Mall Lotte Bintaro. Setelah melakukan penyebaran kuesioner dan mendapatkan data kuesioner dengan 38 responden, maka langkah selanjutnya adalah melakukan pengolahan data dengan metode Servqual. Metode ini dimulai dengan menghitung gap/selisih antara harapan pelanggan mengenai layanan jasa dengan kenyataan pelayanan yang dirasakan pelanggan. Hal tersebut dilakukan dengan cara penyebaran kuesioner melalui media sosial. Perusahaan tidak hanya berfokus pada jasa film namun juga produk makanan dan minuman. Hasil penelitian menunjukkan bahwa seluruh dimensi servqual memiliki nilai negatif, sehingga untuk meningkatkan kepuasan pelanggan, disarankan manajemen perusahaan dapat meningkatkan kualitas pelayanan pada lima dimensi servqual. Atribut yang memiliki nilai negatif terbesar adalah "kualitas produk sesuai harga".
\end{abstract}

Kata Kunci : Servqual, Kualitas jasa, Pelayanan, Produk

*email: fahira.adyaprasetyo@student.upj.ac.id 


\section{PENDAHULUAN}

Selaras dengan perubahan lingkungan bisnis dan teknologi yang begitu cepat, organisasi juga dituntut untuk melakukan perubahan kearah yang lebih baik. Ukuran mengenai seberapa baik tingkat pelayanan yang diberikan mampu memenuhi ekspektasi pelanggan, pada umumnya disebut sebagai sebagai kualitas jasa. Upaya untuk memperbaiki kualitas jasa tidak hanya berdampak positif bagi pelanggan namun dapat juga meningkatkan kepuasan kerja bagi karyawan (Rahayu, Rasid dan Tannady, 2018). Peran untuk mengubah organisasi tidak hanya datang dari tim manajemen namun juga harus datang dari karyawan (Tannady et al., 2019). Penting bagi manajemen untuk meningkatkan motivasi karyawan guna menciptakan performa kerja yang baik (Tannady, Erlyana dan Nurprihatin, 2019). PT. Nusantara Sejahtera Raya khususnya Cinema XXI memiliki visi yaitu "Terus menjadi yang terbaik di dunia dan membanggakan Indonesia, sehingga kita bisa merasakan 25 tahun berikutnya lagi, lagi dan lagi". Oleh karena itu, PT. Nusantara Sejahtera Raya khususnya Cinema XXI yang berada di Lotte Mart Bintaro harus bisa meningkatkan kualitas layanannya termasuk dalam hal produk maupun jasa agar dapat meningkatkan kepercayaan dan kepuasan pelanggan. Tim manajemen perlu menyadari bahwa perkembangan bisnis terus berubah dan tidak tetap sehingga perlu adanya upaya perbaikan berkesinambungan. Ukuran mengenai seberapa baik tingkat pelayanan yang diberikan mampu memenuhi ekspektasi pelanggan, pada umumnya disebut sebagai sebagai kualitas jasa. Upaya untuk memperbaiki kualitas jasa tidak hanya berdampak positif bagi pelanggan namun dapat juga meningkatkan kepuasan kerja bagi karyawan. Peran untuk mengubah organisasi tidak hanya datang dari tim manajemen namun juga harus datang dari karyawan. Dalam kualitas jasa, terdapat lima dimensi karateristik kualitas pelayanan yaitu bukti fisik, daya tanggap, keandalan, jaminan dan empati. Kelima dimensi inilah yang kemudian akan diuji menggunakan metode service quality atau bisa disingkat juga dengan istilah Servqual. Pendekatan yang digunakan untuk mengukur kualitas pelayanan adalah dengan menggunakan metode analisis service quality untuk mengetahui gap antara harapan pelanggan terhadap atribut jasa dan tingkat kepuasan yang dirasakan (Wilujeng et al., 2019).

Oleh karena itu, peneliti melakukan studi tentang evaluasi produk dan pelayanan pada perusahaan menggunakan service quality berdasarkan lima dimensi jasa Servqual. Diharapkan dengan hasil penelitian nantinya dapat membuat perusahaan memaksimalkan kualitas pelayanannya. Berdasarkan latar belakang yang telah dikemukakan, maka rumusan masalah pada penelitian ini adalah mengidentifikasi atribut yang harus di evaluasi dan diperbaiki (tidak memenuhi harapan pelanggan), atribut yang perlu dipertahankan (berhasil memenuhi harapan pelanggan), atribut yang sudah memenuhi harapan pelanggan dan atribut yang perlu dievaluasi dan diperbaiki oleh perusahaan.

\section{LANDASAN TEORI}

\subsection{Kualitas Jasa}

Jasa merupakan suatu bentuk kegiatan yang dilakukan oleh satu orang atau lebih, umumnya sifat jasa adalah tidak berbentuk dan tidak menghasilkan kepemilikan (Kotler dan Keller, 2016; Tanuwijaya dan Tannady, 2019). Penting bagi organisasi untuk dapat meningkatkan kepuasan pelanggan melalui peningkatan kualitas jasa (Lusiani, Yuirafat dan Tannady, 2017). Kualitas jasa merupakan tingkat keunggulan (excellence) yang diharapkan dalam pengendalian atas keunggulan tersebut untuk memenuhi keinginan pelanggan (Tjiptono, 2012). Pengertian lain dari jasa menurut adalah setiap tindakan atau kegiatan yang dapat ditawarkan oleh satu pihak kepada pihak lain, yang pada dasarnya tidak berwujud dan tidak adapun proses ini tidak terkait dengan produk fisik (Kotler dan Keller, 2016). Jasa tidak berwujud, umumnya tidak menyebabkan kepemilikan dari faktor produksi (Wright dan Lovelock, 1999). Jasa merupakan seluruh aktivitas ekonomi dengan luaran selain produk dalam pengertian fisik, dikonsumsi dan diproduksi pada saat bersamaan, memberikan nilai tambah dan secara prinsip tidak berwujud (intangible) bagi pembeli pertamanya (Zeithaml, Bitner dan Gremler, 2018). Oleh karena itu, dapat disimpulkan bahwa jasa merupakan sesuatu hal yang tidak berwujud (intangible) atau dapat pula dikatakan jasa adalah bersifat abstrak. Jasa adalah layanan yang ditawarkan oleh satu pihak kepada pihak yang lain. 


\subsection{Metode Service Quality (Servqual)}

Service Quality merupakan persepsi akan kualitas yang dimiliki oleh pelanggan, baik pelanggan eksternal maupun pelanggan internal (Tannady, Nurprihatin dan Hartono, 2018). Service quality adalah pemenuhan kebutuhan dan keinginan pelanggan serta ketepatan penyampaian untuk mengimbangi harapan pelanggan (Tjiptono, 2012). Kualitas pelayanan didefinisikan sebagai persepsi pelanggan bagaimana layanan memenuhi atau melampaui harapan mereka (Czepiel, Solomon dan Suprenant, 1985; Saghier dan Nathan, 2013). Kepuasan pelanggan merupakan evaluasi purna beli dimana alternatif yang dipilih sekurangkurangnya memberikan hasil (outcome) sama atau melampaui harapan pelanggan, sedangkan ketidakpuasan timbul apabila hasil yang diperoleh tidak memenuhi harapan pelanggan (Blackwell, Miniard dan Engel, 2005). Kualitas dapat diartikan sebagai derajat yang dicapai oleh karakteristik yang berkaitan dalam memenuhi persyaratan (Tjiptono dan Chandra, 2011). Service quality merupakan perbedaan antara harapan dan kenyataan yang diterima oleh pelanggan (Zeithaml, Parasuraman dan Berry, 1985). Kepuasan seseorang dapat diukur dengan cara membandingkan tingkat harapan pelanggan dengan tingkat kepuasan yang dirasakan pelanggan terhadap pelayanan yang perusahaan berikan (Tannady et al., 2017). Kualitas pelayanan merupakan keseluruhan kesan konsumen terhadap inferioritas atau subprioritas organisasi beserta jasa yang ditawarkan (Bitner, Booms dan Mohr, 1994). Definisi kualitas pelayanan menekankan pada ukuran seberapa baik tingkat pelayanan yang diberikan mampu sesuai dengan ekspektasi pelanggan (Smith, Bolton dan Wagner, 1999).

\section{METODOLOGI}

Jenis penelitian yang digunakan dalam penelitian ini adalah penelitian kuantitatif. Metode penelitian kuantitatif dapat diartikan sebagai metode penelitian yang berlandaskan pada filsafat positivisme, digunakan untuk meneliti pada populasi atau sampel tertentu (Sugiyono, 2011). Pengumpulan data dalam penelitian terdiri dari dua langkah yaitu persiapan yang dilakukan sebelum melakukan penelitian seperti mencari buku, jurnal dan landasan teori yang mendukung penelitian seperti teori kualitas jasa dan servqual. Melakukan studi pendahuluan dan studi literatur untuk lebih memahami topik yang diteliti dan merancang kuesioner. Isi kuesioner yang disusun mewakili 5 dimensi dalam kualitas jasa. Tahap kedua adalah Pengamatan, tahap ini memberikan kuesioner kepada responden, menggunakan metode simple random sampling. Jumlah responden dalam penelitian ini adalah warga Jabodetabek yang telah mengunjungi dan menggunakan produk dan jasa dari perusahaan. Setelah melakukan penyebaran kuesioner dan mendapatkan data kuesioner dengan 38 responden, maka langkah selanjutnya adalah melakukan pengolahan data dengan metode Servqual. Metode ini dimulai dengan menghitung gap/selisih antara harapan pelanggan mengenai layanan jasa dengan kenyataan pelayanan yang dirasakan pelanggan.

Tabel 1. Nilai Rata-Rata Gap 5 Terhadap Pernyataan Kualitas Layanan Jasa

\begin{tabular}{cccccc}
\hline \multirow{2}{*}{ Atribut } & \multicolumn{2}{c}{ Harapan Pelayanan } & \multicolumn{2}{c}{ Kenyataan Pelayanan } & \\
\cline { 2 - 5 } & Bobot Nilai & $\begin{array}{c}\text { Rata-Rata Nilai } \\
\text { Harapan }\end{array}$ & Bobot Nilai & $\begin{array}{c}\text { Rata-Rata Nilai } \\
\text { Kenyataan }\end{array}$ & Nilai Gap 5 \\
\hline 1 & 174 & 4.57 & 158 & 4.15 & -0.42 \\
2 & 171 & 4.50 & 157 & 4.13 & -0.37 \\
3 & 167 & 4.39 & 147 & 3.86 & -0.53 \\
4 & 169 & 4.44 & 154 & 4.05 & -0.39 \\
5 & 168 & 4.42 & 142 & 3.73 & -0.69 \\
6 & 168 & 4.42 & 152 & 4.00 & -0.42 \\
7 & 169 & 4.44 & 150 & 3.94 & -0.5 \\
8 & 170 & 4.47 & 152 & 4.00 & -0.47 \\
9 & 164 & 4.31 & 151 & 3.97 & -0.34 \\
10 & 164 & 4.31 & 147 & 3.86 & -0.45 \\
11 & 163 & 4.21 & 146 & 3.84 & -0.37 \\
12 & 175 & 4.60 & 167 & 4.39 & -0.21 \\
\hline
\end{tabular}


Tabel 2. Nilai Rata-rata Gap 5 Berdasarkan Dimensi Servqual

\begin{tabular}{lcccccc}
\hline Dimensi & Atribut & $\begin{array}{c}\text { Jumlah Rata- } \\
\text { Rata } \\
\text { Harapan }\end{array}$ & $\begin{array}{c}\text { Jumlah Rata- } \\
\text { Rata } \\
\text { Kenyataan }\end{array}$ & $\begin{array}{c}\text { Nilai Harapan } \\
\text { Pelayanan }\end{array}$ & $\begin{array}{c}\text { Nilai } \\
\text { Kenyataan } \\
\text { Pelayanan }\end{array}$ & $\begin{array}{c}\text { Nilai } \\
\text { Gap 5 }\end{array}$ \\
\hline Keandalan & 11,12 & 8.81 & 8.23 & 4.405 & 4.115 & -0.29 \\
Daya & 9,10 & 8.62 & 7.65 & 4.31 & 3.825 & -0.485 \\
tanggap & & & & & & \\
Jaminan & $3,4,5$ & 13.25 & 11.64 & 4.417 & 3.88 & -0.537 \\
Empati & $6,7,8$ & 13.33 & 11.94 & 4.443 & 3.98 & -0.463 \\
Bukti fisik & 1,2 & 9.07 & 8.28 & 4.535 & 4.14 & -0.395 \\
\hline
\end{tabular}

Tabel 3. Urutan nilai Gap 5 dari Gap Terkecil Sampai Gap Terbesar

\begin{tabular}{clc}
\hline Atribut & \multicolumn{1}{c}{ Pernyataan } & Nilai Gap 5 \\
\hline 12 & Lokasi mudah dijangkau & -0.21 \\
9 & Karyawan melayani dengan baik & -0.34 \\
2 & Produk tersusun rapi & -0.37 \\
11 & Produk mudah dicari & -0.37 \\
4 & Produk yang ditawarkan berkualitas baik & -0.39 \\
1 & Tempat nyaman dan bersih & -0.42 \\
6 & Karyawan bersikap ramah & -0.42 \\
10 & Saran dan keluhan ditanggapi dengan baik & -0.45 \\
8 & Karyawan menyambut kedatangan pelanggan & -0.47 \\
7 & Karyawan murah senyum & -0.50 \\
3 & Produk lengkap & -0.53 \\
5 & Kualitas produk sesuai harga & -0.69 \\
\hline
\end{tabular}

\section{ANALISIS DAN PEMBAHASAN} 4.1 Hasil Perhitungan Gap

Tabel 1 menunjukkan hasil perhitungan gap/selisih antara harapan dan persepsi pelanggan terhadap pelayanan jasa berdasarkan 12 atribut pernyataan kuesioner.

\subsection{Perhitungan Dimensi Kualitas Jasa Berdasarkan Servqual Gap 5}

Lima dimensi dalam kualitas jasa terdiri dari keandalan (reliability), daya tanggap (responsiveness), jaminan (assurance), empati (empathy), dan bukti fisik (tangibles) (Zeithaml, Parasuraman dan Berry, 1985). Tabel 2 menunjukkan hasil perhitungan nilai rata-rata gap 5 berdasarkan lima dimensi servqual.

Dari Tabel 2 dapat diketahui dimensi yang memiliki gap terbesar sampai dengan yang terkecil. Semakin besar gap yang didapat dari perhitungan gap 5 maka semakin kurang baiknya kualitas dimensi pelayanan jasa tersebut. Dan sebaliknya, semakin kecil gap yang didapat dari perhitungan gap 5 (gap tersebut nol dan positif) maka semakin baik kualitas pelayanan jasanya. Oleh karena itu, prioritas perbaikan pelayanan jasa dilakukan dari gap atau kesenjangan terbesar. Berdasarkan Tabel 2 dapat dilihat bahwa dimensi kualitas jasa jaminan (assurance) memiliki nilai gap 0.537, dimensi kualitas jasa daya tanggap (responsiveness) memiliki nilai gap -0.485 , dimensi kualitas jasa empati (empathy) memiliki nilai gap -0.463, dimensi kualitas jasa bukti fisik (tangibles) memiliki nilai gap -0.395 , dan dimensi kualitas jasa keandalan (reliability) memiliki nilai gap -0.29. Berdasarkan pengolahan data, diperoleh seluruh dimensi memiliki nilai gap yang negatif. Hal ini berarti kelima dimensi service quality pada perusahaan masih perlu ditingkatkan untuk dapat semakin memenuhi kepuasan dan permintaan pelanggan.

Tabel 3 menunjukkan tidak ada atribut yang bernilai gap positif. 12 atribut pernyataan bernilai gap negatif (perlu adanya evaluasi dan perbaikan). Atribut dengan nilai gap negatif terkecil adalah lokasi mudah dijangkau (atribut nomor 12) dengan nilai gap -0.21, sedangkan atribut dengan nilai gap negatif terbesar adalah kualitas produk sesuai harga (atribut nomor 5) dengan nilai gap -0.69. 


\section{SIMPULAN}

Atribut pernyataan yang bernilai negatif (perlu adanya evaluasi dan perbaikan) diantaranya adalah atribut nomor 1 yaitu "tempat nyaman dan bersih" yang bernilai -0.42 , atribut nomor 2 yaitu "produk tersusun rapih" yang bernilai -0.37 , atribut nomor 3 yaitu "produk lengkap" yang bernilai -0.53, atribut nomor 4 yaitu "produk yang ditawarkan berkualitas baik" yang bernilai -0.39, atribut nomor 5 yaitu "kualitas produk sesuai harga" yang bernilai -0.69 dan atribut nomor 6 yaitu "karyawan bersikap ramah" yang bernilai -0.42 , atribut nomor 7 yaitu "karyawan murah senyum" yang bernilai -0.5 , atribut nomor 8 yaitu "karyawan menyambut kedatangan pelanggan" yang bernilai -0.47 , atribut nomor 9 yaitu "karyawan melayani dengan baik" yang bernilai -0.34 , atribut nomor 10 yaitu "saran dan keluhan ditanggapi dengan baik" yang bernilai 0.45 , atribut nomor 11 yaitu "produk mudah dicari" yang bernilai -0.37 , atribut nomor 12 yaitu "lokasi mudah dijangkau" yang bernilai 0.21. Dimensi jasa yang belum memenuhi harapan pelanggan (perlu adanya evaluasi dan perbaikan) adalah dimensi kualitas jasa jaminan (assurance) memiliki nilai gap -0.537, dimensi kualitas jasa daya tanggap (responsiveness) memiliki nilai gap -0.485 , dimensi kualitas jasa empati (empathy) memiliki nilai gap -0.463 , dimensi kualitas jasa bukti fisik (tangibles) memiliki nilai gap -0.395, dan dimensi kualitas jasa keandalan (reliability) memiliki nilai gap 0.29 .

\section{DAFTAR PUSTAKA}

Bitner, M. J., Booms, B. H. dan Mohr, L. A. (1994) "Critical Service Encounters: The Employee's Viewpoint," Journal of Marketing, 58(4), hal. 95-106. doi: 10.1177/002224299405800408.

Blackwell, R. D., Miniard, P. W. dan Engel, J. F. (2005) Consumer Behavior. 10 ed. Cincinnati: South-Western College Pub.

Czepiel, J. A., Solomon, M. R. dan Suprenant, C. F. (1985) The Service Encounter: Managing Employee/Customer Interaction in Service Business. Lanham: Lexington Books.

Kotler, P. dan Keller, K. L. (2016) Marketing Management. 15 ed. London: Pearson Education Limited. doi: 10.1080/08911760903022556.

Lusiani, M., Yuirafat, A. dan Tannady, H.
(2017) "Analisis Kepuasan Pengguna BPJS dan Non BPJS terhadap Layanan Rumah Sakit dengan Model Quality Funcion Deployment," in Prosiding Seminar Nasional Akuntansi dan Bisnis. Bandung: Fakultas Ekonomi Universitas Widyatama, hal. 1011-1017.

Rahayu, M., Rasid, F. dan Tannady, H. (2018) "Effects of Self Efficacy, Job Satisfaction, and Work Culture Toward Performance of Telemarketing Staff in Banking Sector," South East Asia Journal of Contemporary Business, Economics and Law, 16(5), hal. 47-52.

Saghier, N. El dan Nathan, D. (2013) "Service Quality Dimensions and Customers' Satisfactions of Banks in Egypt," in Proceedings of 20th International Business Research Conference. Dubai, hal. 1-13.

Smith, A. K., Bolton, R. N. dan Wagner, J. (1999) "A Model of Customer Satisfaction with Service Encounters Involving Failure and Recovery," Journal of Marketing Research, 36(3), hal. 356372. doi: $10.2307 / 3152082$.

Sugiyono (2011) Metode Penelitian Kuantitatif Kualitatif dan $R \& D$. Bandung: Alfabeta.

Tannady, H. et al. (2017) “Analisis Kualitas Jasa pada Maskapai Penerbangan Rute Domestik Tarif Menengah Kebawah dengan Menggunakan Metode Servqual dan Metode Importance and Performance Analysis," in Prosiding Seminar Nasional Teknologi dan Informatika. Kudus: Fakultas Teknik Universitas Muria Kudus, hal. 523-529.

Tannady, H., Erlyana, Y. dan Nurprihatin, F. (2019) "Effects of Work Environment and Self-Efficacy Toward Motivation of Workers in Creative Sector in Province of Jakarta, Indonesia," Quality - Access to Success, 20(172), hal. 165-168.

Tannady, H., Nurprihatin, F. dan Hartono, H. (2018) "Service Quality Analysis of Two of the Largest Retail Chains with Minimart Concept in Indonesia," Business: Theory and Practice, 19, hal. 177-185. doi: 10.3846/BTP.2018.18.

Tannady, Hendy et al. (2019) "The Effect of Organizational Culture and Employee Engagement on Job Performance of Healthcare Industry in Province of Jakarta, Indonesia," Quality: Access to 
Success, 20(169), hal. 18-22.

Tanuwijaya, C. dan Tannady, H. (2019) "Evaluasi Produk dan Pelayanan di Toko Buku Gramedia Emporium Pluit Mall Jakarta Utara Menggunakan Service Quality," in Prosiding Seminar Nasional Sains dan Teknologi Informasi. Medan: STMIK Budi Darma, hal. 25-28.

Tjiptono, F. (2012) Strategi Pemasaran. 3 ed. Yogyakarta: Andi.

Tjiptono, F. dan Chandra, G. (2011) Service, Quality dan Satisfaction. Yogyakarta: Andi.

Wilujeng, F. R. et al. (2019) "Meningkatkan Kepuasan Pelanggan pada Dua Bisnis ECommerce Terbesar di Indonesia dengan Menggunakan Analisis Servqual dan
IPA," in Prosiding Seminar Nasional Sains dan Teknologi. Jakarta: Fakultas Teknik Universitas Muhammadiyah Jakarta, hal. 1-9.

Wright, L. K. dan Lovelock, C. H. (1999) Principles of Service Marketing and Management. 2 ed. Upper Saddle River: Prentice Hall.

Zeithaml, V. A., Bitner, M. J. dan Gremler, D. D. (2018) Services Marketing. 7 ed. New York: McGraw-Hill Education.

Zeithaml, V. A., Parasuraman, A. dan Berry, L. L. (1985) "Problems and Services Strategies in Marketing," Journal of Marketing, 49(2), hal. 33-46. doi: $10.2307 / 1251563$. 